\title{
Selective suppression of bacterial contaminants by process conditions during lignocellulose based yeast fermentations
}

Eva Albers ${ }^{1}$, Emma Johansson ${ }^{1,2}$, Carl Johan Franzén ${ }^{1}$ and Christer Larsson ${ }^{1 *}$

\begin{abstract}
Background: Contamination of bacteria in large-scale yeast fermentations is a serious problem and a threat to the development of successful biofuel production plants. Huge research efforts have been spent in order to solve this problem, but additional ways must still be found to keep bacterial contaminants from thriving in these environments. The aim of this project was to develop process conditions that would inhibit bacterial growth while giving yeast a competitive advantage.

Results: Lactic acid bacteria are usually considered to be the most common contaminants in industrial yeast fermentations. Our observations support this view but also suggest that acetic acid bacteria, although not so numerous, could be a much more problematic obstacle to overcome. Acetic acid bacteria showed a capacity to drastically reduce the viability of yeast. In addition, they consumed the previously formed ethanol. Lactic acid bacteria did not show this detrimental effect on yeast viability. It was possible to combat both types of bacteria by a combined addition of $\mathrm{NaCl}$ and ethanol to the wood hydrolysate medium used. As a result of $\mathrm{NaCl}+$ ethanol additions the amount of viable bacteria decreased and yeast viability was enhanced concomitantly with an increase in ethanol concentration. The successful result obtained via addition of $\mathrm{NaCl}$ and ethanol was also confirmed in a real industrial ethanol production plant with its natural inherent yeast/bacterial community.

Conclusions: It is possible to reduce the number of bacteria and offer a selective advantage to yeast by a combined addition of $\mathrm{NaCl}$ and ethanol when cultivated in lignocellulosic medium such as wood hydrolysate. However, for optimal results, the concentrations of $\mathrm{NaCl}+$ ethanol must be adjusted to suit the challenges offered by each hydrolysate.
\end{abstract}

Keywords: ethanol, fermentation, contaminants, bacteria, lignocellulosic, yeast, Saccharomyces

\section{Background}

Contamination by bacteria in industrial scale yeast fermentations is a huge problem with serious economic consequences. Such operations are not carried out under aseptic conditions and Lactobacilli, which are usually considered to be the most frequent contaminants, thrive under the very same conditions as the yeast Saccharomyces cerevisiae [1-3]. In some conditions and for certain products the bacteria can provide added value in the form of flavor, taste, and so on, but the

\footnotetext{
* Correspondence: christer.larsson@chalmers.se

'Department Chemical and Biological Engineering, Chalmers University of Technology, 41296 Gothenburg, Sweden Full list of author information is available at the end of the article
}

levels must be maintained within certain limits [4]. In other processes, such as production of biofuels like ethanol, bacterial contamination causes reductions in yield and/or productivity with a deteriorating economy of the process as a consequence. Despite massive amounts of time and effort spent on these matters, bacterial contamination is still a serious problem and a threat to the successful development of commercial bio-based fuel production. Traditional methods for keeping bacterial contaminants at a tolerable level include introduction of very low $\mathrm{pH}$, for example, between 2 and 3 [5], and more modern techniques rely on the ancient knowledge that hops can provide not only a favorable taste of various beverages but also protection against bacterial
Ciomed Central 
decomposition of the product [6,7]. However, these methods do not always function as expected, and there is still a need to find additional ways of preventing bacteria from flourishing in these environments. Another option sometimes considered is the use of antibiotics. However, this is questionable from an economic point of view but even more important is the increasing awareness and fear of the ever-increasing spread of bacterial resistance due to massive misuse of these compounds.

This investigation was undertaken in order to develop process conditions that would present a selective advantage to the yeast while suppressing growth and product formation of bacteria. In addition, several of the conditions were selected to be relevant for socalled high gravity or high solids fermentation as this would offer high product concentration and an improved economy of the ethanol production process [8]. In order to make relevant comparisons of the selective effect on yeast and bacteria between different conditions, we isolated numerous bacterial isolates from the industrial ethanol production plant in Örnsköldsvik, Sweden from which the yeast strain used was originally isolated. The process conditions selected were enhanced levels of sugar, sodium chloride and ethanol as well as low $\mathrm{pH}$. Initially these conditions were tested one by one using pure cultures of yeast and bacteria. Later on, cocultures of yeast and bacteria were studied in competition experiments and combinations of stress factors were also included. The results showed that a combination of $\mathrm{NaCl}+$ ethanol additions to the wood hydrolysate could suppress growth of bacteria while yeast viability and ethanol production was favored.

\section{Results and Discussion}

In order to identify what bacterial species that should be included in the study sampling of the microbial community at an industrial ethanol production plant, Domsjö Fabriker AB in Örnsköldsvik, Sweden, were performed. The most abundant species of Lactobacillus seemed to be Lactobacillus buchneri and Lactobacillus plantarum, that is, most of the isolates obtained belonged to these two species. A full report concerning identified bacterial species and their respective growth behavior, stress tolerance and so on, will be reported in a separate publication. The species of Lactobacillus and Acetobacter that are included in this investigation were all obtained from this plant with the exception of Lactobacillus fermentum that was obtained from the American Type Culture Collection (ATCC; http:// www.lgcstandards-atcc.org/). This latter strain was used as a reference as it had previously been investigated in a similar type of study [9].
Viability of bacterial contaminants with or without cocultivation with yeast

Even though bacteria such as Lactobacilli frequently contaminate industrial yeast fermentations, none of the tested Lactobacilli strains included in this study could grow or even maintain its viability in the hydrolysate without the presence of yeast (Figure 1). In fact, it is worth mentioning that none of the more than 15 Lactobacilli isolates obtained managed to multiply in the absence of yeast (data not shown). Acetobacter, showed an entirely different behavior and the viability was well preserved, or even slightly enhanced, during the incubation time of 3 days (Figure 1).

In cocultures of bacteria and yeast there was a tendency to a slight improvement in preservation of viability of $L$. fermentum although on average the increase is less than 1 $\log$ unit (Figures 1 and 2). However, the most striking effect of these coculture experiments was the severe effect on the viability of the yeast $S$. cerevisiae from the presence of Acetobacter (Figure 2). Without bacteria, S. cerevisiae managed to grow and multiply close to five generations in the hydrolysate used, but in the presence of Acetobacter there was a drastic reduction in the viability of the yeast after a growth period of 1 to 2 days (Figure 2).

The effect of nutrient supplementation (yeast extract) on viability of bacteria

One reason for the somewhat increasing viability of Lactobacilli in the presence of yeast cells could be that

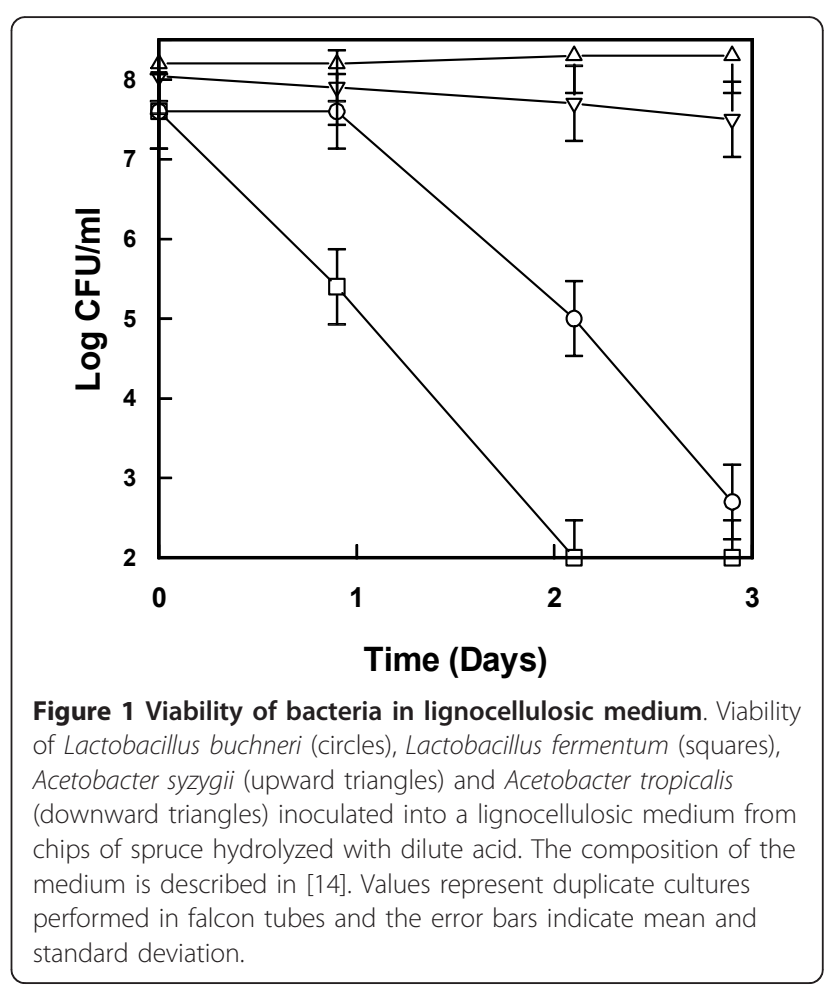




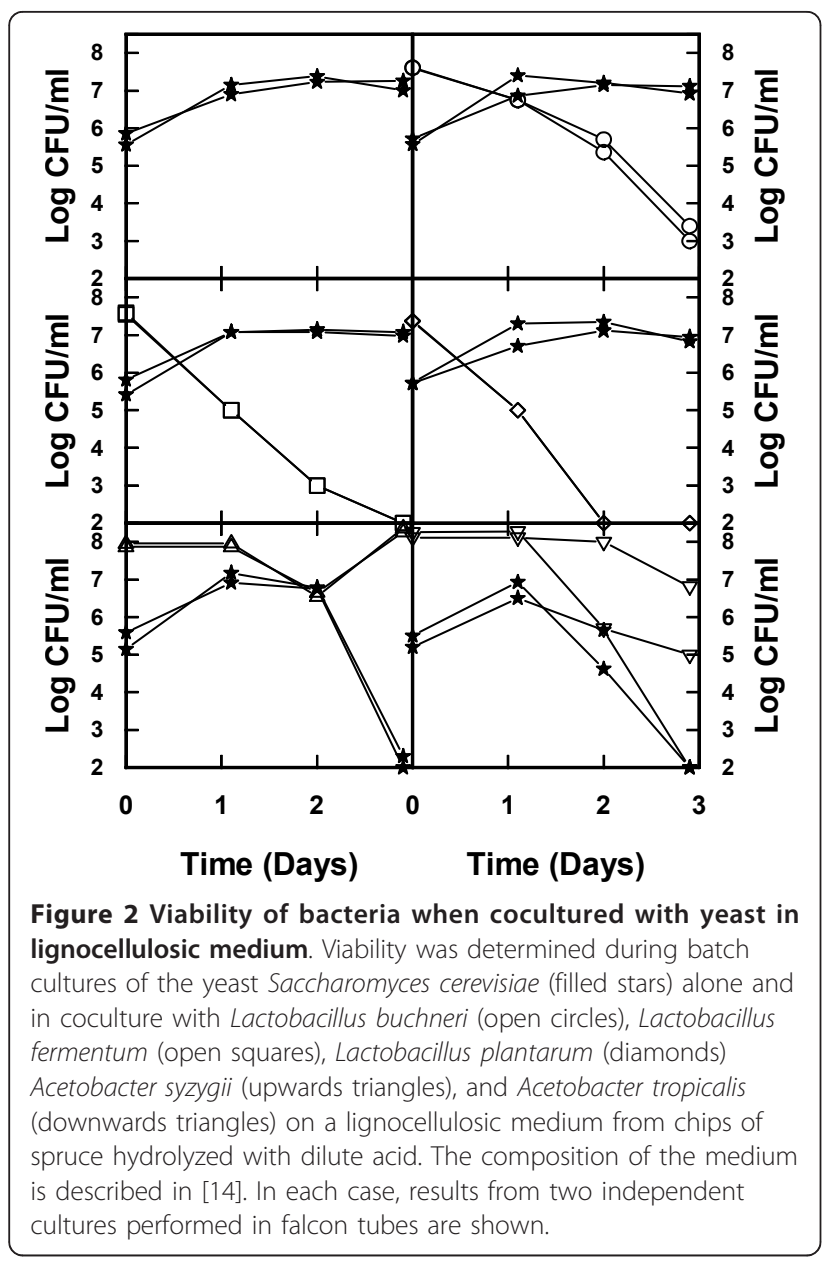

yeast will offer some additions of essential nutrients to the bacteria [10]. To test this hypothesis we added yeast extract to the hydrolysate, but no effect whatsoever on viability of Lactobacilli could be detected (Figure 3). Most probably, the effect of yeast additions on viability of bacteria originate from the fact that the activity of $S$. cerevisiae will detoxify the hydrolysate $[11,12]$ perhaps with some added value from nutrient availability.

Similarly, no effect on yeast viability and multiplication could be detected as a result of yeast extract additions to the hydrolysate (Figure 3).

\section{Growth and product formation during cocultivation of yeast and Lactobacillus or Acetobacter}

Coculture experiments revealed large effects on growth and viability of yeast and bacteria when coexisting in the lignocellulosic medium. How did this affect metabolism and major catabolic products such as ethanol, acetate and lactic acid?

The ethanol concentrations reached about $12 \mathrm{~g} / \mathrm{l}$ and there was no negative effect due to the presence of Lactobacilli (Figure 4A, 4B). Lactic acid

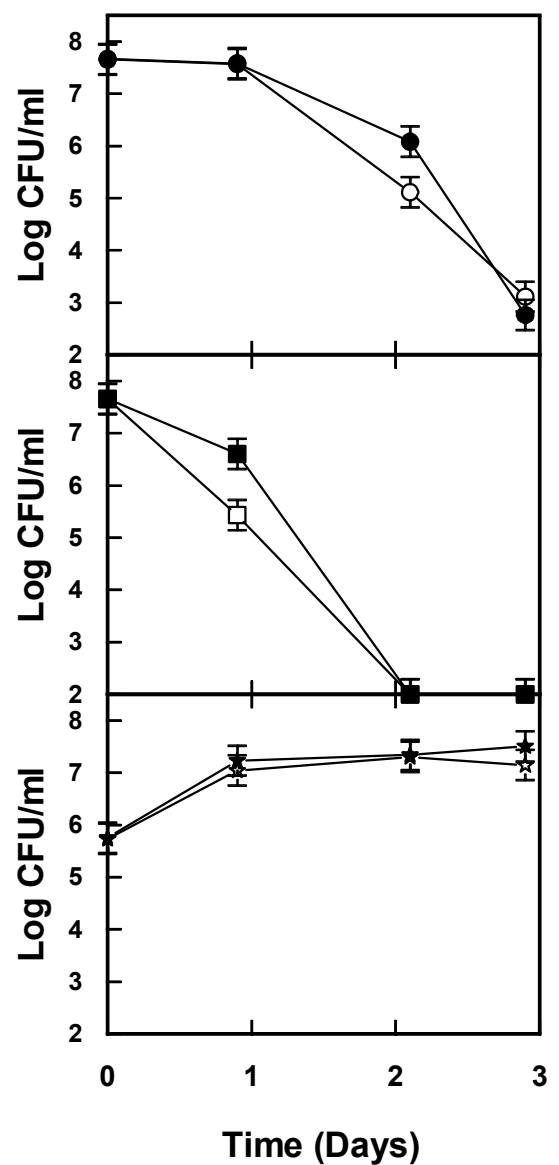

Figure 3 Viability of bacteria and yeast in lignocellulosic medium with and without addition of yeast extract. Viability of Lactobacillus buchneri (circles), Lactobacillus fermentum (squares), and Saccharomyces cerevisiae (stars) inoculated into lignocellulosic medium with (filled symbols) or without (open symbols) the addition of $1 \mathrm{~g} / \mathrm{l}$ of yeast extract. The composition of the medium is described in [14]. Values represent duplicate cultures performed in falcon tubes and error bars indicate mean and standard deviation.

concentrations were very low, below $0.1 \mathrm{~g} / \mathrm{l}$, throughout the duration of the experiment and no production or consumption was detected. Acetate was found at initial concentrations of about $3.0 \mathrm{~g} / \mathrm{l}$ and a slow consumption resulted in final concentrations between 2.0 to $2.3 \mathrm{~g} / \mathrm{l}$ (Figure $4 \mathrm{~A}$ ).

A completely different picture emerged when S. cerevisiae was mixed with Acetobacter in cocultures. In this case there was production of ethanol during the initial $24 \mathrm{~h}$ but this was followed by declining ethanol concentrations concomitant with an increase in acetate concentrations (Figure 4B), similar to what is normally observed during growth of Acetobacter [13]. Obviously, the Acetobacter not only has a very negative effect on the viability of the yeast (Figure 2) but also consumes a substantial part of the previously formed ethanol. 

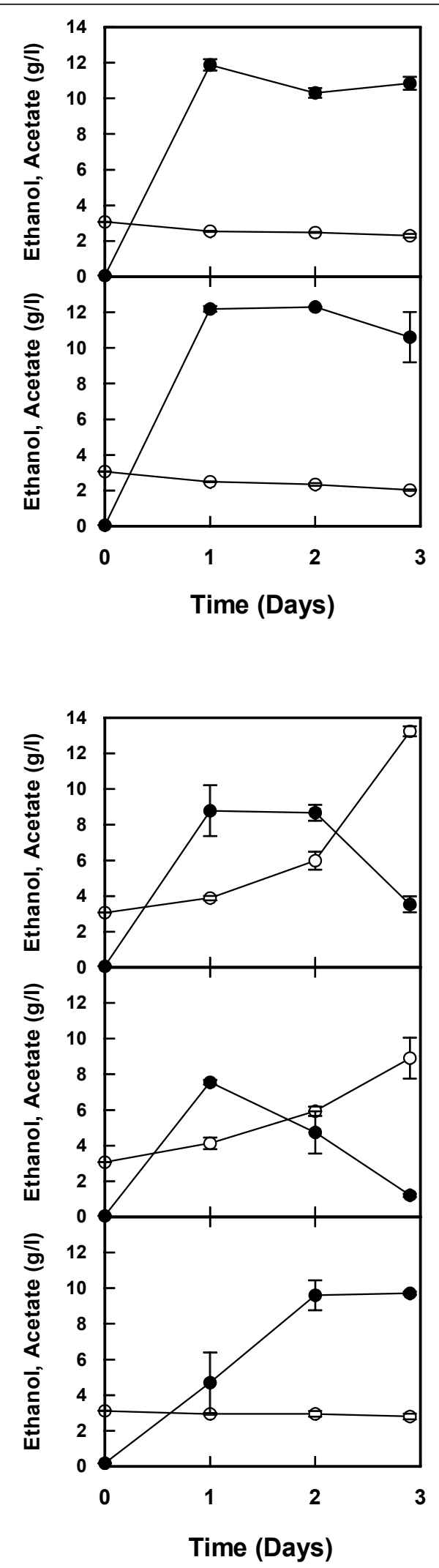

Figure 4 (a) Ethanol (filled circles) and acetate (open circles) concentrations in cocultures of yeast and lactic acid bacteria.
Samples were taken from cocultures of Saccharomyces cerevisiae and Lactobacillus buchneri (upper panel) or S. cerevisiae and Lactobacillus fermentum (lower panel) inoculated in a lignocellulosic medium from chips of spruce hydrolyzed with dilute acid. The composition of the medium is described in [14]. Values represent duplicate cultures performed in falcon tubes and error bars indicate minimum/maximum values. (b) Ethanol (filled circles) and acetate (open circles) concentrations in cocultures of yeast and acetic acid bacteria. Samples were taken from cocultures of $\mathrm{S}$. cerevisiae and Acetobacter syzygii (upper panel), S. cerevisiae and Acetobacter tropicalis (middle panel) or pure culture of $\mathrm{S}$. cerevisiae (lower panel) inoculated in a lignocellulosic medium from chips of spruce hydrolyzed with dilute acid. The composition of the medium is described in [14]. Values represent duplicate cultures performed in falcon tubes and error bars indicate minimum/maximum values.

The selective effect on yeast and bacteria from addition of $\mathrm{NaCl}$, sugar, ethanol, and low $\mathrm{pH}$

Due to the potentially detrimental effect of bacterial contaminations on yeast fermentations it was decided to assess whether it was possible to choose process conditions that would selectively inhibit bacteria with minimum effects on the yeast. A systematic study on the effect of low $\mathrm{pH}$ and additions of $\mathrm{NaCl}$, sugar, ethanol on the growth of yeast and bacteria isolated from industrial ethanol production plants was performed. The results regarding stress tolerance in various yeast strains can be found in [14]. Concerning bacteria, more than 15 isolates of Lactobacilli as well as 3 strains reported to be relevant in similar environments, together with several isolates of Acetobacter were included in this investigation (Albers and Larsson, unpublished results). Of these, a subset of eight representative Lactobacilli, six yeast, and two Acetobacter strains were chosen for a wider analysis at several treatment levels in rich yeast extract/peptone/dextrose (YPD) or MRS media. These screening experiments were performed using pure cultures. The results were evaluated using multiple regression analysis. No single parameter could be expected to selectively favor yeast at the expense of bacteria. However, the fitted response surfaces (Figure 5) indicated that Lactobacilli may be more sensitive than yeast to combinations of elevated $\mathrm{NaCl}$ and ethanol concentrations. The Acetobacter strains grew very slowly in this experimental set up in comparison to the Lactobacilli and yeasts in all tested conditions.

\section{Identification of optimum combinations of $\mathrm{NaCl}+$ ethanol selectively inhibiting bacteria}

In order to test the hypothesis that enhanced levels of $\mathrm{NaCl}$ together with ethanol could selectively inhibit bacteria, a number of cocultures with yeast, L. buchneri, $L$. plantarum Acetobacter syzygii and Acetobacter tropicalis (all isolated from Domsjö Fabriker AB) were performed using a variety of combinations between $\mathrm{NaCl}$ and 


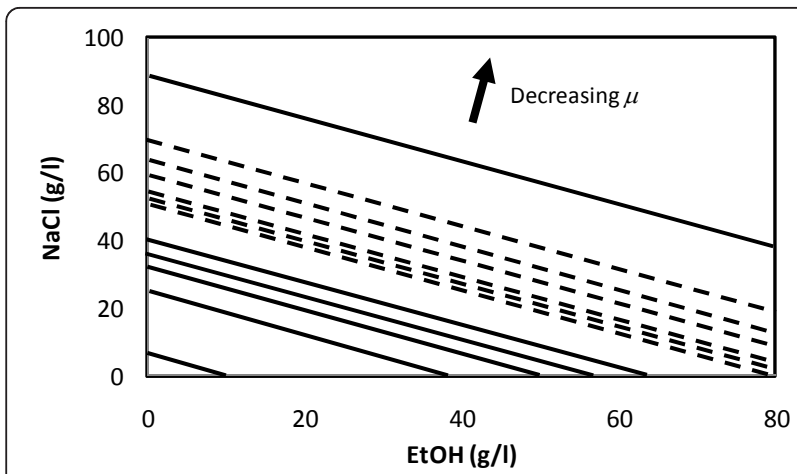

Figure 5 Predicted limits of ethanol and $\mathrm{NaCl}$ concentrations at which the specific growth rate equals $0.1 \mathrm{~h}^{-1}$ of yeasts (dashed lines) and lactic acid bacteria (solid lines). The area above each line indicate combinations of $\mathrm{NaCl}$ and ethanol concentrations leading to growth rates below $0.1 \mathrm{~h}^{-1}$ for (top to bottom) Lactobacillus plantarum ATCC14431, commercially available baker's yeast (Jästbolaget AB, Sollentuna, Sweden), Saccharomyces cerevisiae CCUG53310, diploid S. cerevisiae X2180aa, diploid S. cerevisiae CEN. PK122, haploid S. cerevisiae X2180-1A, haploid S. cerevisiae CEN. PK113-7D, Lactobacillus fermentum ATCC14931, Lactobacillus paracasei ATCC25598, and industrial isolates of Lactobacillus buchneri, Lactobacillus pantheris and L. plantarum from Domsjö Fabriker, Örnsköldsvik, Sweden. Growth rates were estimated by multiple regression analysis of results from 435 batch cultures on rich media (yeast extract/peptone/dextrose (YPD) for yeast, MRS for bacteria). Growth rates were predicted at $\mathrm{T}=30^{\circ} \mathrm{C}, \mathrm{pH}=5$, lactic acid concentration $4 \mathrm{~g} / \mathrm{l}$, and glucose concentration $100 \mathrm{~g} / \mathrm{l}$. ethanol (Figure 6). To evaluate the effectiveness of this treatment a calculation was performed after $24 \mathrm{~h}$ of incubation concerning the increase in viable yeast cells and decrease in viable bacteria, respectively. The conditions finally chosen for more rigorous testing were $25 \mathrm{~g} /$ $1 \mathrm{NaCl}+40 \mathrm{~g} / \mathrm{l}$ ethanol and $50 \mathrm{~g} / \mathrm{l} \mathrm{NaCl}+20 \mathrm{~g} / \mathrm{l}$ ethanol, since these combinations resulted in the largest decrease in bacterial viability while yeast could still maintain its viability. The former condition resulted in an increase in viable yeast cells almost similar to the increase obtained by the control without additions while the number of bacteria showed a more than tenfold decrease (Figure 6). Raising the $\mathrm{NaCl}$ concentration to $50 \mathrm{~g} / \mathrm{l}$ and reducing ethanol to $20 \mathrm{~g} / \mathrm{l}$ provoked a very drastic reduction in viable bacteria, close to 1,000 -fold, while there was still an increase in viability of yeast during the $24 \mathrm{~h}$ period of testing (Figure 6).

\section{Enhancing yeast viability and productivity by a combination of $\mathrm{NaCl}$ and ethanol additions}

The successful treatment in terms of increased yeast viability and reduction of bacteria by these additions were verified by cultivations of cocultures in bioreactors. In the absence of $\mathrm{NaCl}$ and ethanol the bacteria multiplied in the lignocellulosic medium while yeast viability showed a negative trend (Figure 7). A totally opposite

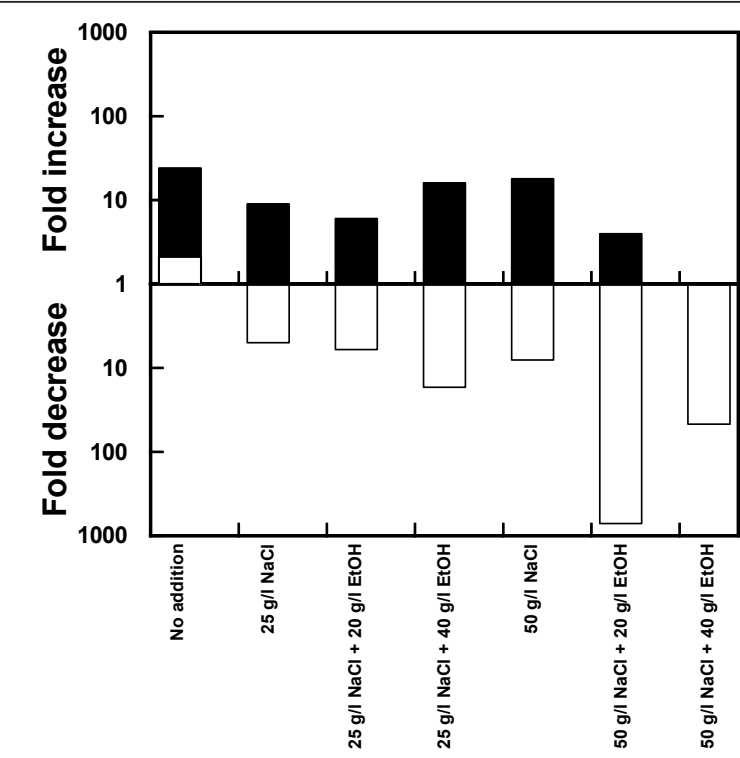

Figure 6 Fold change in viable yeast (closed bars) and viable bacteria (open bars) after $24 \mathrm{~h}$ incubation in lignocellulosic medium with and without additions of ethanol and/or $\mathrm{NaCl}$. The fold change of viable yeast and bacteria was calculated after 24 $\mathrm{h}$ incubation in falcon tubes of a mixture of the yeast Saccharomyces cerevisiae and the bacteria Lactobacillus buchneri, Lactobacillus fermentum, Acetobacter syzygii and Acetobacter tropicalis inoculated into a dilute acid spruce hydrolysate medium with and without various additions of ethanol and/or $\mathrm{NaCl}$. A missing bar means that the change is lower than onefold.

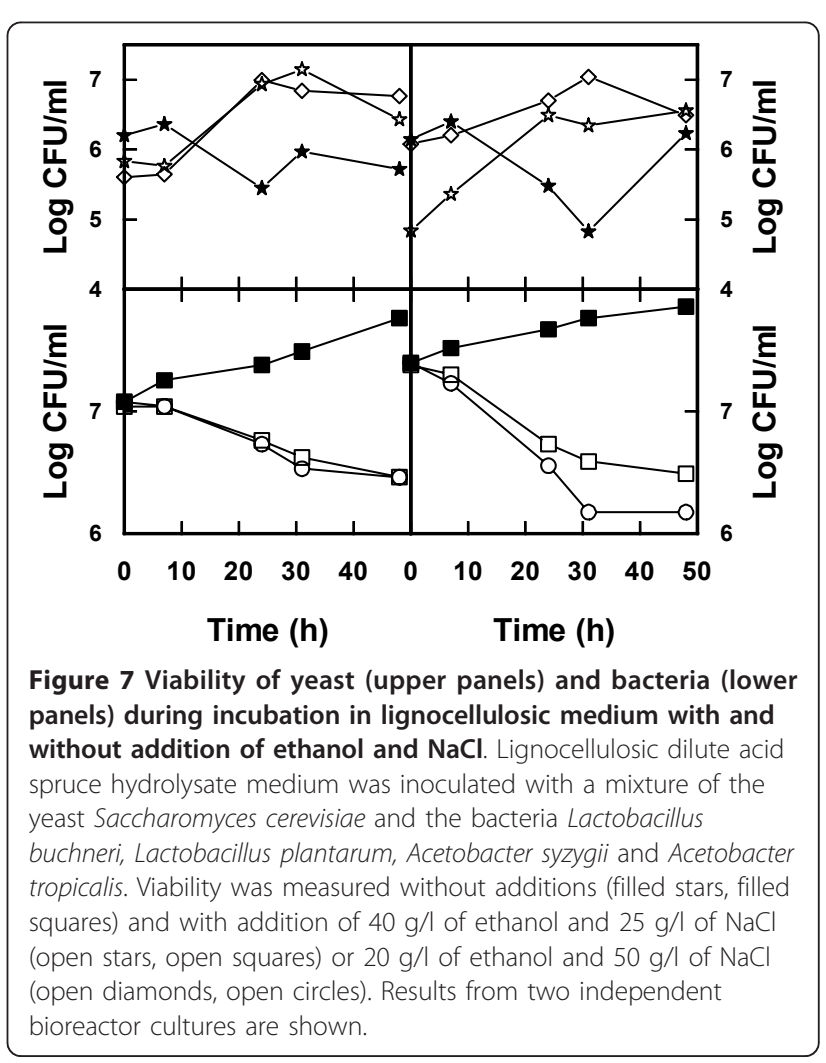


effect was seen on addition of $\mathrm{NaCl}+$ ethanol, that is, there was a substantial decrease in bacteria and improved growth of yeast (Figure 7). Also in terms of ethanol production, $\mathrm{NaCl}+$ ethanol additions turned out to be successful as there was indeed an increase in the amount of ethanol produced compared with results obtained using lignocellulosic medium without these additions (Figure 8). To some extent these results were somewhat surprising since both $\mathrm{NaCl}$ as well as ethanol additions in pure cultures also showed a negative effect on the yeast $S$. cerevisiae. Apparently, reducing the viability of bacteria is crucial to having a net positive effect on the yeast performance in these mixed cultures.

\section{Verification of laboratory results in an industrial ethanol production plant}

In order to test whether additions of $\mathrm{NaCl}$ together with ethanol could be a strategy to reduce the amount of bacteria also at a real industrial ethanol production plant, experiments were carried out at Domsjö Fabriker AB in Örnsköldsvik, Sweden. Samples were obtained from the production plant at this site and various combinations of $\mathrm{NaCl} /$ ethanol additions were tested. It should be kept in mind that this kind of test will include the response of the entire microbial community at the selected site and not only some selected isolates. Preferably, these tests should be repeated at different time points as the

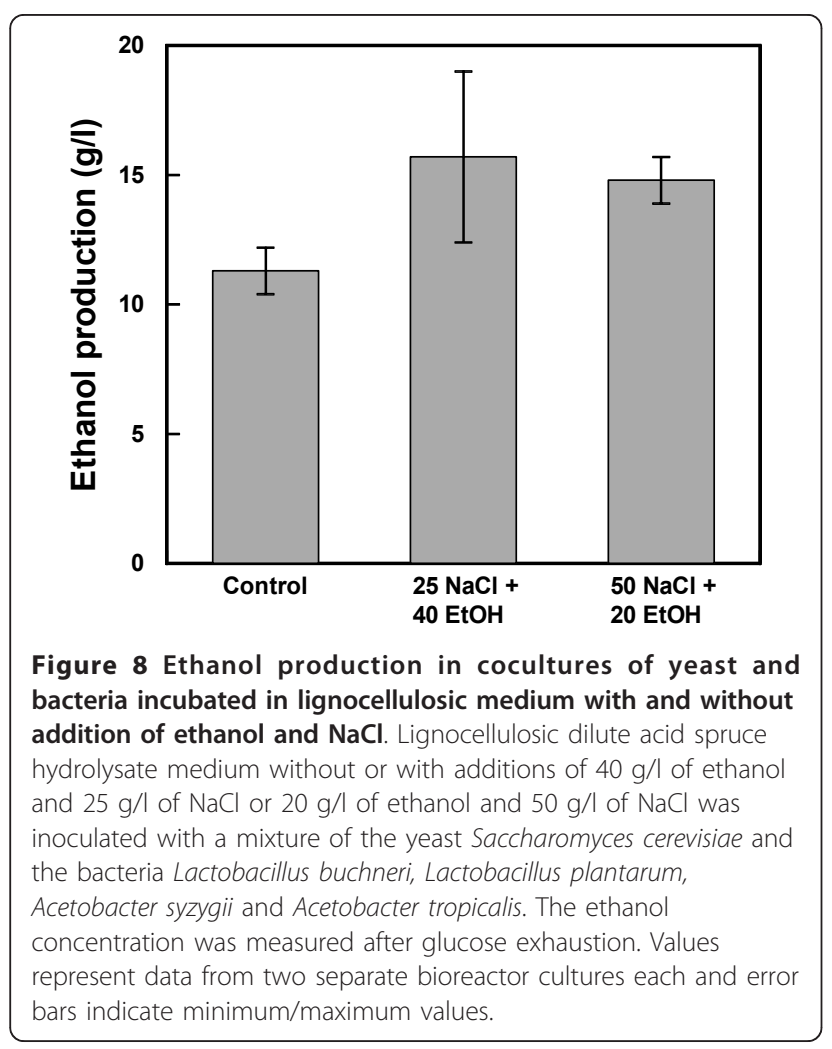

conditions and composition of the microbial flora change over time. As it turned out it was indeed possible to restrict bacterial contaminants by additions of $\mathrm{NaCl}$ and ethanol in a real industrial environment (Figure 9). However, it did require extensive testing and fine tuning of the concentrations used, and in our case a combination of $25 \mathrm{~g} / 1 \mathrm{NaCl}$ and $12.5 \mathrm{~g} / \mathrm{l}$ ethanol added was the most effective combination (Figure 9).

\section{Conclusions}

Acetic acid bacteria can potentially be a much more serious threat than lactic acid bacteria as contaminants of industrial scale yeast fermentations. Acetic acid bacteria showed a capacity to drastically reduce the viability of yeast cells as well as consuming the previously formed ethanol. Lactic acid bacteria did not show any of these characteristics. A combined addition of $\mathrm{NaCl}$ and ethanol during cultivation in wood hydrolysate could be used to reduce the number of bacteria and to selectively support the viability of yeast cells and thereby increase the concentration of ethanol.

A strategy to implement this in an industrial setting could be to add ethanol by recycling of process streams and to start the process using only a fraction of the total volume. This will potentially offer a kick-start for yeast in comparison to bacteria and preclude the necessity of adding large total amounts of $\mathrm{NaCl}$ and $\mathrm{EtOH}$.

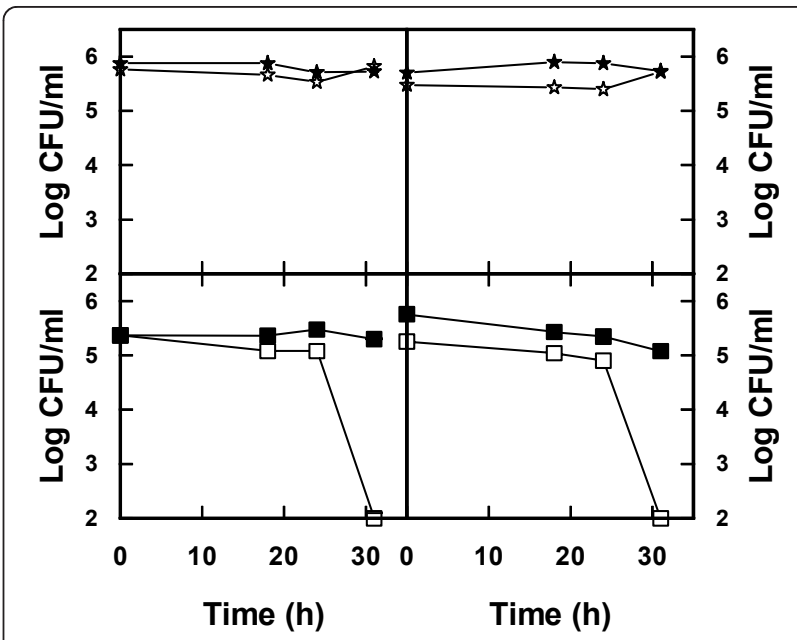

Figure 9 Viability of yeast (upper panels) and bacteria (lower panels) in a sludge obtained from an industrial ethanol production unit with and without additions of ethanol and $\mathrm{NaCl}$. Sludge with its natural microbial flora of yeast and bacteria, obtained from an ethanol production plant (Domsjö Fabriker, Örnsköldsvik, Sweden), was used for inoculating spent sulfite liquor medium. Viability of yeast and bacteria was assessed for non-treated samples (closed symbols) and samples subjected to addition of 12.5 $\mathrm{g} / \mathrm{l}$ of ethanol and $25 \mathrm{~g} / \mathrm{l}$ of $\mathrm{NaCl}$ (open symbols). Results from two entirely different cultivations are shown. 


\section{Methods}

\section{Strains}

An industrial strain of $S$. cerevisiae was used (CCUG53310, Culture Collection University of Göteborg, Göteborg, Sweden) [15]. This strain was originally isolated from an industrial ethanol production plant, Domsjö Fabriker AB, Örnsköldsvik, Sweden. Lactic acid bacteria were obtained from a culture collection, Lactobacillus fermentum (ATCC14931) or isolated from Domsjö Fabriker AB, L. buchneri, L. plantarum. Acetic acid bacteria, Acetobacter tropicalis, A. syzygii, were isolated from the same industrial plant. The isolated bacteria were species determined by a combination of API test (bioMerieux, France) and 16S RNA gene sequencing.

\section{Cultivations}

Inoculum cultures were grown in YPD medium $(10 \mathrm{~g} / \mathrm{l}$ yeast extract (Sigma-Aldrich St. Louis, USA), 20 g/l peptone (Nordic Biolabs, Taby, Sweden), 20 g/l glucose (Merck, Darmstadt, Germany)) for yeast and MRS medium (Oxoid, Hampshire, England) for bacteria for 1 to 1.5 days at $30^{\circ} \mathrm{C}$ in falcon tubes or shake flasks depending on culture volume.

The cultivations were performed in a lignocellulosic hydrolysate of spruce chips pretreated with dilute acid, a composition determined previously [14]. The pH was adjusted to 5.0 with ammonia (Merck, Darmstadt, Germany) and the hydrolysate medium was filter sterilized before usage.

For cocultivations on a small scale in $50 \mathrm{ml}$ falcon tubes, the cells in the inocula were harvested after 1 day by centrifugation, resuspended in sterile water and the optical density at $610 \mathrm{~nm}\left(\mathrm{OD}_{610}\right)$ was measured. The hydrolysate (6 or $10 \mathrm{ml}$ ) was inoculated with cells (yeast and/or bacteria) and water in a total of $45 \mu \mathrm{l} / \mathrm{ml}$ hydrolysate to give an initial $\mathrm{OD}_{610}$ of 0.05 for yeast and at 0.09 for bacteria. The lid was closed and the tubes were incubated at $30^{\circ} \mathrm{C}$ in a rotary shaker and monitored for up to 4 days. Samples for medium analyses were centrifuged ( $2 \mathrm{~min}$, at minimum $14,000 \mathrm{~g}$ ) and stored at $-20^{\circ} \mathrm{C}$ before analysis.

Cocultivations on a large bench scale were performed with 11 of medium using 31 bioreactors (Belach Bioteknik $\mathrm{AB}$, Stockholm, Sweden) operated at $30^{\circ} \mathrm{C}$ with a stirring rate of $300 \mathrm{rpm}$ and no gas inlet. The initial pH was set to 5.0 with ammonia (Merck, Darmstadt, Germany) during the preparation of medium and the decrease during cultivations was always less than $0.5 \mathrm{pH}$ units.

\section{Determination of bacteria and yeast viability at an industrial production plant}

The start inoculum was a mixture of microorganisms harvested from the Domsjö Fabriker industrial ethanol production plant located in Örnsköldsvik, Sweden. This mixture (sludge) contained the complete microbiological community existing in an industrial ethanol fermentation plant: mainly yeast, lactic acid bacteria and acetic acid bacteria.

This microbiological community was cultivated for 32 $\mathrm{h}$ at $30^{\circ} \mathrm{C}$ in spent sulfite liquor supplemented with 10.2 $\mathrm{ml}$ 25\% ammonium (Merck, Darmstadt, Germany) and $171 \mathrm{mg} / \mathrm{KH}_{2} \mathrm{PO}_{4}$ (Merck, Darmstadt, Germany) with and without addition of $\mathrm{NaCl}$ (Merck, Darmstadt, Germany) (25 g/l) + ethanol (VWR, Leuven, Belgium) (12.5 $\mathrm{g} / \mathrm{l})$. The $\mathrm{pH}$ was adjusted to 5.0 by addition of $5 \mathrm{M}$ $\mathrm{NaOH}$ (Merck, Darmstadt, Germany) prior to fermentation. The cultivations were performed in $300 \mathrm{ml}$ Erlenmeyer flasks with a total volume of $200 \mathrm{ml}$.

Measurements of the cell viability were performed by colony forming unit (CFU) count.

\section{Analyses}

Metabolites in the medium (ethanol, acetic acid, lactic acid) were analyzed using commercial enzymatic kits assays (R-Biopharm GmbH, Darmstadt, Germany) with adapted volumes in microtiter plates. Absorbance was measured with a Fluostar Galaxy plate reader (BMG Labtechnologies, Offenburg, Germany).

CFU determinations were performed on agar plates with YPD for yeast (when bacteria was present in large numbers, $20 \mu \mathrm{l}$ of $50 \mathrm{~g} / \mathrm{l}$ ampicillin (AppliChem, Darmstadt, Germany) was added to each plate) and MRS for bacteria with $0.1 \mathrm{~g} / 1$ cycloheximide (Merck, Darmstadt, Germany)to suppress growth of yeast. Each dilution was spread on two or three plates. The plates were incubated at $30^{\circ} \mathrm{C}$ for 2 days for yeast and for 3 days for bacteria to establish distinct colonies before counting.

Multiple regression analysis of the specific growth rate as a function of $\mathrm{pH}$, temperature, and concentrations of $\mathrm{NaCl}$, glucose, ethanol and lactic acid was performed using the software Modde 9.0 (Umetrics AB, Umea, Sweden).

\section{Acknowledgements}

The project was funded by the Swedish energy agency, project no. 30188-1 and 30188-2, the Kempe foundation and the county administrative board of Vasternorrland, which is gratefully acknowledged.

\section{Author details}

${ }^{1}$ Department Chemical and Biological Engineering, Chalmers University of Technology, 41296 Gothenburg, Sweden. ${ }^{2}$ Processum Biorefinery Initiative, 89180 Örnsköldsvik, Sweden.

\section{Authors' contributions}

EA participated in the design of the study, performed all the laboratory scale experiments and took part in interpretation of results and writing of the manuscript. EJ participated in the design of and performed all the experiments at industrial scale, and took part in interpretation of results and writing of the manuscript. CJF performed the multiple regression analysis and took part in interpretation of results and writing of the manuscript. $\mathrm{CL}$ designed the study, took part in interpretation of results and was the main author. All authors read and approved the final manuscript. 


\section{Competing interests}

The authors declare that they have no competing interests.

Received: 7 October 2011 Accepted: 20 December 2011

Published: 20 December 2011

\section{References}

1. Bischoff KM, Skinner-Nemec KA, Leathers TD: Antimicrobial susceptibility of Lactobacillus species isolated from commercial ethanol plants. J Ind Microbiol Biotechnol 2007, 34:739-744.

2. Schell DJ, Dowe N, Ibsen KN, Riley CJ, Ruth MF, Lumpkin RE: Contaminant occurrence, identification and control in a pilot-scale corn fiber to ethanol conversion process. Bioresour Technol 2007, 98:2942-2948.

3. Skinner KA, Leathers TD: Bacterial contaminants of fuel ethanol production. J Ind Microbiol Biotechnol 2004, 31:401-408

4. Priest FG, Campbell I: Brewing Microbiology New York, NY: Kluwer Academic/ Plenum Press; 2003.

5. Gibson BR, Lawrence SJ, Leclaire JP, Powell CD, Smart KA: Yeast responses to stresses associated with industrial brewery handling. FEMS Microbiol Rev 2007, 31:535-569.

6. Simpson WJ, Smith AR: Factors affecting antibacterial activity of hop compounds and their derivatives. J Appl Bacteriol 1992, 72:327-334.

7. Suzuki K, lijima K, Sakamoto K, Sami M, Yamashita H: A review of hop resistance in beer spoilage lactic acid bacteria. J Int Brew 2006, 112:173-191

8. Jorgensen H, Vibe-Pedersen J, Larsen J, Felby C: Liquefaction of lignocellulose at high-solids concentrations. Biotechnol Bioeng 2007, 96:862-870.

9. Narendranath NV, Hynes SH, Thomas KC, Ingledew WM: Effects of Lactobacilli on yeast-catalyzed ethanol fermentations. Appl Environ Microbiol 1997, 63:4158-4163.

10. Stenberg K, Bollok M, Reczey K, Galbe M, Zacchi G: Effect of substrate and cellulase concentration on simultaneous saccharification and fermentation of steam-pretreated softwood for ethanol production. Biotechnol Bioeng 2000, 68:204-210.

11. Almeida JRM, Modig T, Petersson A, Hahn-Hagerdahl B, Lidén G, GorwaGrauslund MF: Increased tolerance and conversion of inhibitors in lignocellulosic hydrolysates by Saccharomyces cerevisiae. J Chem Technol Biotechnol 2007, 82:340-349.

12. Taherzadeh MJ, Gustafsson L, Niklasson C, Liden G: Conversion of furfural in aerobic and anaerobic batch fermentation of glucose by Saccharomyces cerevisiae. J Biosci Bioeng 1999, 87:169-174.

13. Raspor P, Goranovic D: Biotechnological applications of acetic acid bacteria. Crit Rev Biotechnol 2008, 28:101-124.

14. Albers $E$, Larsson C: A comparison of stress tolerance in YPD and industrial lignocellulose-based medium among industrial and laboratory yeast strains. J Ind Microbiol Biotechnol 2009, 36:1085-1091.

15. Purwadi R, Brandberg T, Taherzadeh M: A possible industrial solution to ferment lignocellulosic hydrolyzate to ethanol: continuous cultivation with flocculating yeast. Int J Mol Sci 2007, 8:920-932.

doi:10.1186/1754-6834-4-59

Cite this article as: Albers et al: Selective suppression of bacterial contaminants by process conditions during lignocellulose based yeast fermentations. Biotechnology for Biofuels 2011 4:59.

\section{Submit your next manuscript to BioMed Central and take full advantage of:}

- Convenient online submission

- Thorough peer review

- No space constraints or color figure charges

- Immediate publication on acceptance

- Inclusion in PubMed, CAS, Scopus and Google Scholar

- Research which is freely available for redistribution

Submit your manuscript at www.biomedcentral.com/submit
Biomed Central 